\title{
Functional Mapping and $\mathrm{Ca}^{2+}$ Regulation of Nicotinic Acetylcholine Receptor Channels in Rat Hippocampal CA1 Neurons
}

\author{
Leonard Khiroug, Rashid Giniatullin, Rebecca C. Klein, Dmitriy Fayuk, and Jerrel L. Yakel \\ Laboratory of Signal Transduction, National Institute of Environmental Health Sciences, Research Triangle Park, North Carolina 27709
}

\begin{abstract}
Diverse subtypes of nicotinic acetylcholine receptors (nAChRs), including fast-desensitizing $\alpha 7$-containing receptors thought to be $\mathrm{Ca}^{2+}$-permeable, are expressed in the CNS, where they appear to regulate cognitive processing and synaptic plasticity. To understand the physiological role of nAChRs in regulating neuronal excitability, it is important to know the distribution of functional receptors along the surface of neurons, whether they can increase $\left[\mathrm{Ca}^{2+}\right]_{\mathrm{i}}$, and/or are regulated by $\mathrm{Ca}^{2+}$. We mapped the distribution of receptors on the membrane of rat hippocampal CA1 stratum radiatum interneurons and pyramidal cells in acute slices by recording nAChR-mediated currents elicited by local UV laser-based photolysis of caged carbachol in patch-clamped neurons. The local application $(\sim 7 \mu \mathrm{m}$ patches $)$ allowed mapping of functional nAChRs along the soma and dendritic tree, whereas the fast uncaging minimized the effects of desensitization of $\alpha 7$-containing nAChRs and allowed us to measure the kinetics of responses. The $\alpha 7$-containing nAChRs were the predominant subtype on interneurons, and were located primarily at perisomatic sites ( $<70 \mu \mathrm{m}$ from the soma; in contrast to the more uniform distribution of glutamate receptors); no currents were detectable on pyramidal neurons. The activation of nAChRs increased $\left[\mathrm{Ca}^{2+}\right]_{\mathrm{i}}$, indicating that these native receptors in acute slices are significantly $\mathrm{Ca}^{2+}$-permeable, consistent with previous observations made with recombinant receptors. In addition, they exhibited strong desensitization, the rate of recovery from which was controlled by $\left[\mathrm{Ca}^{2+}\right]_{\mathrm{i}}$. Our results demonstrate the strategic location and $\mathrm{Ca}^{2+}$ regulation of $\alpha 7$-containing nAChRs, which may contribute to understanding their involvement in hippocampal plasticity.
\end{abstract}

Key words: nicotinic; acetylcholine; hippocampus; interneuron; patch clamp; channel

\section{Introduction}

Neuronal nicotinic acetylcholine receptors (nAChRs) are widely expressed in the CNS and PNS where they are involved in a variety of physiological processes, including cognition and development (for review, see Jones et al., 1999). Because these receptors are known to participate in various forms of synaptic plasticity (Hunter et al., 1994; Fujii and Sumikawa, 2001; Ji et al., 2001; McGehee, 2002), it is also important to know how they are regulated by various signal transduction cascades (e.g., $\mathrm{Ca}^{2+}$ dependent processes).

In the rat hippocampus, GABAergic interneurons receive cholinergic input from the medial septum-diagonal band complex (MSDB) of the basal forebrain (Frotscher and Léránth, 1985; Woolf, 1991) and express diverse subtypes of somatodendritic $\mathrm{nAChRs,} \mathrm{including} \mathrm{fast} \mathrm{desensitizing} \alpha 7$-containing receptors, as well as a variety of non- $\alpha 7$ types (for review, see Jones et al.,

Received June 10, 2003; revised Aug. 11, 2003; accepted Aug. 14, 2003.

We thank C. Erxleben and D. Armstrong for advice in preparing this manuscript.

Correspondence should be addressed to Jerrel L. Yakel, National Institute of Environmental Health Sciences, F2-08, P.0. Box 12233, 111 T. W. Alexander Drive, Research Triangle Park, NC 27709. E-mail:yakel@niehs.nih.gov.

L. Khiroug's present address: Neuroscience Center, P.0. B0X 65 (Viikinkaari 1), 00014 University of Helsinki, Finland.

R. Giniatullin's present address: Biophysics Sector and INFM Unit, International School for Advanced Studies (SISSA), Via, Beirut 4, 34014, Trieste, Italy.

Copyright $\odot 2003$ Society for Neuroscience $\quad$ 0270-6474/03/239024-08\$15.00/0
1999). The $\alpha 7$-containing nAChRs, both heterologously expressed and native to cultured neurons, have been shown to be highly $\mathrm{Ca}^{2+}$-permeable (Bertrand et al., 1993; Séguéla et al., 1993; Castro and Albuquerque, 1995; Berg and Conroy, 2002). Because $\mathrm{Ca}^{2+}$ regulates a variety of signal transduction cascades and plays a key role in the short- and long-term regulation of nAChRs (Berg and Conroy, 2002; Quick and Lester, 2002), this is likely one mechanism to underlie the role of nAChRs in regulating synaptic plasticity in the hippocampus (Ji et al., 2001; McGehee, 2002). However to date, whether activation of nAChRs in acute rat hippocampal slices can directly regulate cytoplasmic $\mathrm{Ca}^{2+}$ levels $\left(\left[\mathrm{Ca}^{2+}\right]_{\mathrm{i}}\right)$ was unknown.

To understand the physiological role of $\mathrm{nAChRs}$ in regulating neuronal excitability, it is important to know the distribution of functional receptors along the surface of the neurons. This requires the application of a nAChR agonist, which is both spatially restricted and fast, since $\alpha 7$-containing $\mathrm{nAChRs}$ are known to desensitize rapidly (McGehee and Role, 1995; Khiroug et al., 2002; Quick and Lester, 2002). Thus, we elicited nAChRmediated currents through local ( $\sim 7 \mu \mathrm{m}$ membrane patches) UV laser-based photolysis of caged carbachol, while simultaneously recording membrane currents using patch-clamp techniques. The extremely rapid kinetics of local photolysis of caged carbachol ( $\sim 100 \mu \mathrm{sec}$ ) (Niu and Hess, 1993) allowed us to dramatically reduce or completely eliminate the effects of desensiti- 
A
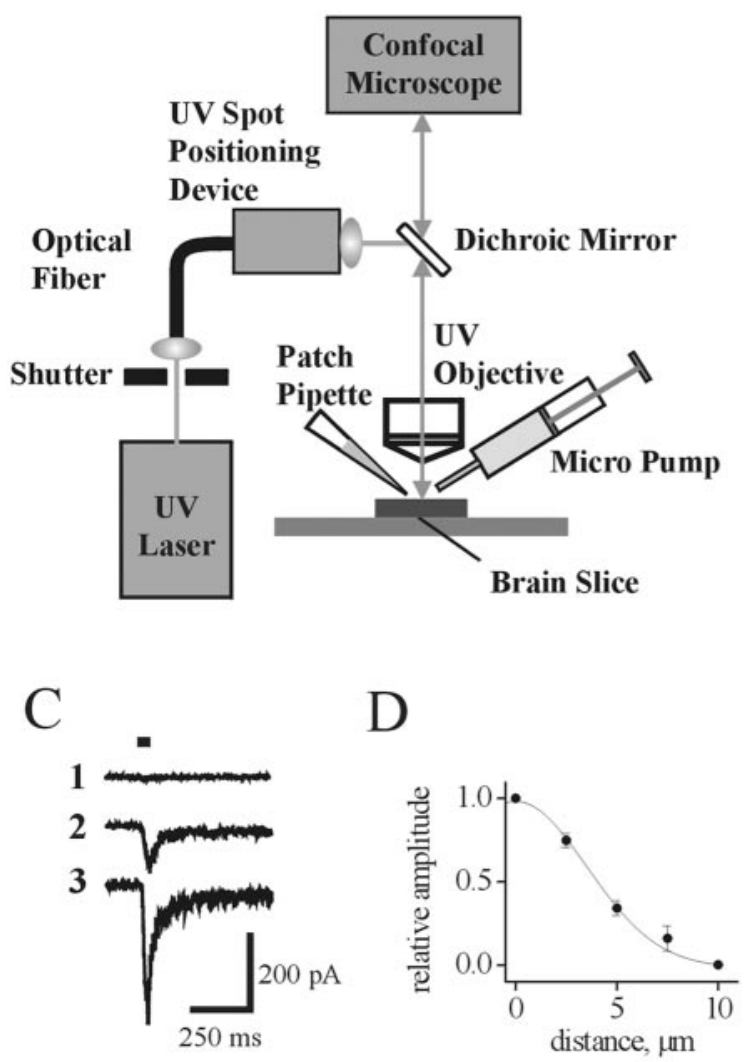

Figure 1. Membrane currents activated by local uncaging of carbachol. $A$, Schematic diagram illustrating the experimental setup used for local photolysis of caged carbachol, confocal microscopy, and electrophysiological recordings. $B, A$ confocal image (3D-reconstructed) of a fluo-4-filled CA1 hippocampal interneuron in the acute slice. Circles indicate the positions of the uncaging spot. C, Currents recorded via the somatic patch pipette in response to carbachol uncaging at individual positions shown in $B$. Horizontal bar indicates duration of the UV flash. D, Plot of peak current amplitude versus distance between the center of the uncaging spot and the dendrite. A Gaussian fit of the data (obtained from five cells) yielded a half-width of $\sim 7 \mu \mathrm{m}$. E, Dependence of peak current amplitude on UV laser power falls along the rising phase of a Boltzmann sigmoidal function (solid and dashed lines). Data were obtained from seven cells. The extrapolated UV power causing a half-maximal response is $1.35 \mathrm{~mW}$.

zation on peak current amplitude. We found that $\alpha 7$-containing receptors were the predominant subtype of nAChRs on interneurons and were located mostly at perisomatic sites, whereas no nAChR-mediated currents were detected on pyramidal neurons. In addition, we show that the activation of these nAChRs directly increased $\left[\mathrm{Ca}^{2+}\right]_{\mathrm{i}}$ and was followed by strong desensitization; the recovery from desensitization ( $23 \mathrm{sec}$ under control conditions) was much faster (i.e., $6 \mathrm{sec}$ ) when we dialyzed cells with the $\mathrm{Ca}^{2+}$ chelator BAPTA. This information should help to elucidate the physiological role of these receptors in hippocampal excitability and plasticity.

\section{Materials and Methods}

Slice preparation. Standard techniques were used to prepare $350-\mu \mathrm{m}$ thick acute hippocampal slices from 14- to 21-d-old rats (Pettit et al., 2001). Briefly, rats were anesthetized with halothane (Sigma, St. Louis, $\mathrm{MO})$ and decapitated. Brains were quickly removed and placed into an ice-cold oxygenated artificial CSF (ACSF) containing (in mM): $119 \mathrm{NaCl}$, $2.5 \mathrm{KCl}, 1.3 \mathrm{MgCl}_{2}, 2.5 \mathrm{CaCl}_{2}, 1 \mathrm{NaH}_{2} \mathrm{PO}_{4}, 26.2 \mathrm{NaHCO}_{3}$, and 11 glucose. After dissection, brain chunks were glued to the stage of a vibratome (VT1000S; Leica, Nussloch, Germany) for slicing while immersed in the cooled oxygenated ACSF. Slices were then used for recordings within $\sim 6$ $\mathrm{hr}$, after at least $1 \mathrm{hr}$ of recovery period.

Electrophysiology. Whole-cell patch-clamp recordings were performed from CA1 stratum radiatum interneurons and pyramidal neurons. Patch pipettes (Garner 7052 glass, with resistances of 3-4 M $\Omega$ ) were filled with a solution that contained (in mM): $120-130$ potassium or cesium gluconate, $2 \mathrm{NaCl}, 4$ $\mathrm{Na}_{2} \mathrm{ATP}, 0.4 \mathrm{Na}_{2} \mathrm{GTP}, 4-5 \mathrm{MgCl}_{2}, 0.2$ fluo-4, and 20 HEPES, pH 7.2-7.3. BAPTA (20 mm) was added as indicated. Slices were superfused at room temperature $\left(18-22^{\circ} \mathrm{C}\right)$ with ACSF. CNB-caged carbachol or glutamate (Molecular Probes, Eugene, OR) was added (2 mm final concentration) to the ACSF and delivered to the vicinity of the patch-clamped cell using an UltraMicroPump II syringe pump (WPI, Sarasota, FL) at the flow rate of $10 \mu \mathrm{l} / \mathrm{min}$. Quartz syringe tips ( $250 \mu \mathrm{m}$ internal diameter) of the syringe were placed just above the slice surface to ensure homogenous coverage of the mapped portion of the interneuronal dendritic arbor. The use of the syringe pump allowed reliable application of maximal concentrations of caged carbachol or glutamate during continuous superfusion of the slice with fresh oxygenated ACSF, thus avoiding recycling of small volumes, which may cause slice damage. Synaptic activity was blocked with TTX $(1 \mu \mathrm{M})$ added to the ACSF. In some experiments, 1 or $10 \mu \mathrm{M}$ atropine was also added to block putative muscarinic AChR-mediated responses; in those experiments in which it was used, atropine never affected the uncaging-induced currents. Cells were clamped using an Axopatch 200B amplifier (Axon Instruments, Foster City, CA) at a holding potential of $-70 \mathrm{mV}$ unless otherwise indicated, and holding potential values were corrected for a junction potential of $10 \mathrm{mV}$. Currents were recorded and analyzed using pClamp software (Axon Instruments). Statistical analyses were performed using Origin software (Microcal, Northampton, MA). Averaged data were presented as mean \pm SEM. Statistical significance was tested using a Student's $t$ test. Recordings were analyzed only if the holding current was $<100 \mathrm{pA}$ when cells were voltage clamped at $-70 \mathrm{mV}$. For studying the properties of the action potentials, neurons were recorded from under current-clamp conditions, and current was injected to either depolarize neurons to induce spiking. Neurons were defined as regular-spiking if the rate of action potential firing evoked by minimal depolarization was $<40 \mathrm{~Hz}$. In some experiments (as indicated), responses were induced by pressure application of either ACh or carbachol (100-200 msec duration pulses at $10-20$ psi pressure was delivered via a glass pipette placed 20-30 $\mu \mathrm{m}$ from the cell body using a Picospritzer II; General Valve Company, Fairfield, NJ).

Local photolysis. Interneurons were visualized using a fast-scanning confocal microscope (Radiance 2100; Bio-Rad). Fluo-4 (0.2 mm; Molecular Probes) was dialyzed into the cell via the patch pipette, and its fluorescence was excited with $488 \mathrm{~nm}$ light and recorded using a $515 \pm 15$ $\mathrm{nm}$ bandpass filter. For local photolysis of caged carbachol or glutamate, the 351-364 nm output of a continuous emission $8 \mathrm{~W}$ argon-ion laser (Spectraphysics Model 165) was delivered, via a multimode optical fiber (OZ Optics, Ontario, Canada) and a precision UV spot positioning device (Prairie Technologies, Middleton, WI), through an Olympus (Tokyo, Japan) $40 \times$ water-immersion objective (Fig. 1 A). Focusing the UV beam on the interneuronal membrane yielded an uncaging spot of $\sim 7$ $\mu \mathrm{m}$ in diameter (see the Results for details). Moving the uncaging spot through the recording field and visualization of its position before the UV flash was achieved by means of a red photodiode attached to the cartridge moving the optical fiber output. An electronic shutter (Uniblitz) was used to control the duration of the light pulse.

Imaging of $\left[\mathrm{Ca}^{2+}\right]_{i}$. Changes in intracellular $\mathrm{Ca}^{2+}$ levels $\left(\left[\mathrm{Ca}^{2+}\right]_{\mathrm{i}}\right)$ in response to pressure application of either ACh or carbachol were assessed 
with conventional fura-2 fluorescent imaging techniques using an Eclipse E600FN upright microscope (Nikon, Tokyo, Japan) with a $40 \times$ fluorescent water-immersion objective, a Lambda DG-4 light source (Sutter Instruments, Novato, CA) equipped with a stabilized xenon arc lamp $(175 \mathrm{~W})$ and four-channel filter interchange system, and a Cascadecooled $\left(-40^{\circ} \mathrm{C}\right) 16$-bit digital camera (Roper Scientific). The AQM Advance imaging software (Kinetic Imaging) was used to acquire and store images for off-line analysis and to synchronize with membrane current recordings. Fura-2 pentapotassium salt (200-400 $\mu \mathrm{M}$; Molecular Probes) was dialyzed into the cell via the patch pipette, its fluorescence was alternately excited with 340 and $380 \mathrm{~nm}$ light, and pairs of images were recorded using a $510 \mathrm{~nm}$ emission filter at $5 \mathrm{~Hz}$ with $50 \mathrm{msec}$ exposure time for each wavelength used. Different ranges of image binning (from $1 \times 1$ to $8 \times 8$ ) were used depending on fluorescence strength from each particular cell. A region of interest was selected, and the 340/ 380 ratio of fluorescence intensities was calculated using the imaging software. The ratio values were then converted to $\left[\mathrm{Ca}^{2+}\right]_{\mathrm{i}}$ levels according to the calibration curve obtained using the $\mathrm{Ca}^{2+}$ calibration kit (Molecular Probes).

\section{Results}

\section{Currents activated by local uncaging of carbachol}

In acute slices of rat hippocampus, the soma and dendrites of CA1 stratum radiatum interneurons and pyramidal cells were visualized by dialysis with fluo-4 $(0.2 \mathrm{~mm})$ via the patch pipette. After allowing 5-10 min for the dye to diffuse to distal parts of the dendritic tree, the uncaging spot was positioned at the region of interest, as indicated in Figure $1 B$. Caged carbachol $(2 \mathrm{~mm}$ in ASCF) was applied extracellularly (at least $5 \mathrm{~min}$ before uncaging, along with the $\mathrm{Na}^{+}$channel blocker TTX, at $1 \mu \mathrm{M}$ ) to the vicinity of the interneuron through the $250 \mu \mathrm{m}$ tip of a syringe. When the UV laser beam path was positioned at the cell body or dendrites of the voltage-clamped interneuron, brief UV pulses (15-25 msec; up to $\sim 1.3 \mathrm{~mW}$ laser power at the objective) induced membrane currents, because of the rapid photolysis $(\sim 100 \mu \mathrm{sec})$ (Niu and Hess, 1993) of caged carbachol, with rapid onset and decay (Fig. $1 C$, trace 3). For $15 \mathrm{msec}$ pulses, which was the duration used for most of the mapping studies, the rise time (10-90\%) was $8.2 \pm$ $0.2 \mathrm{msec}(n=31$ cells $)$. After reaching peak amplitude during the flash, the response amplitude would decay only slightly (most likely because of some receptor desensitization) to reach a value of $96 \pm 1 \%(n=31$ cells $)$ at the end of the 15 msec uncaging pulse. For $25 \mathrm{msec}$ duration pulses, the amplitudes decayed to a value of $89 \pm 3 \%$ ( $n=7$ cells). This suggests that desensitization was not likely to affect the peak amplitude of responses (see below). The average amplitude of responses at the soma was $300 \pm$ $70 \mathrm{pA}$ ( $n=8$ cells). Despite the local nature and relatively brief duration of the carbachol uncaging pulses, the amplitude of the carbachol-induced currents occasionally reached $1 \mathrm{nA}$. However, when the beam position was $10 \mu \mathrm{m}$ or more away from the cell, little or no current was detected (Fig. 1C, trace 1). The resulting current amplitude was plotted versus distance from the cell (to a region free of the dendrites of the cell). Fitting a Gaussian function to the data obtained in five similar experiments yielded a half-width value of $7.4 \pm 1 \mu \mathrm{m}(n=5$ cells) (Fig. $1 D)$, suggesting that the effective photolysis of caged carbachol occurred only within a small volume around the focal point of the UV laser beam.

To construct a dose-response curve, we plotted the amplitude of uncaging responses at different UV laser power levels (between 0.1 and $1.3 \mathrm{~mW}$ ) at a constant flash duration (either 15 or $25 \mathrm{msec}$ ) (Fig. $1 E)$. Peak current amplitudes for each cell ( $n=7$ cells) were normalized to that obtained at $0.7 \mathrm{~mW}$ and averaged. The data could be fitted with a Boltzmann sigmoidal function, and the extrapolated UV power producing half-maximal responses was estimated to be $1.35 \mathrm{~mW}$ from this relation. This suggests that the responses studied

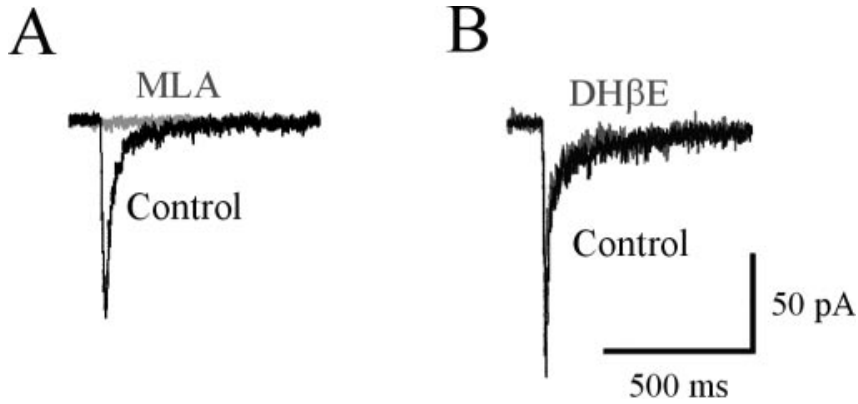

Figure 2. Brief uncaging pulses of carbachol activate $\alpha 7$-containing nAChRs. Currents elicited by brief ( $25 \mathrm{msec}$ ) UV pulses of carbachol are completely blocked by the $\alpha 7$ subunit-specific antagonist MLA (10 nм) $(A)$, but are unaffected by the competitive antagonist of non- $\alpha 7$ $\mathrm{nAChRs,} \mathrm{DH} \beta \mathrm{E}(10 \mu \mathrm{m})(B)$.

here were well below the saturation level, and therefore is another indication that peak responses were not significantly affected by receptor desensitization.

\section{Pharmacological properties of uncaging-induced currents}

Because rat hippocampal interneurons are known to express several subtypes of functional nAChRs, including $\alpha 7$-containing and a variety of non- $\alpha 7$ types, we used specific nAChR antagonists to identify the subunit composition of receptors activated under our experimental conditions. The nAChR-mediated currents induced by uncaging pulses of carbachol to the soma or dendrites of interneurons were completely blocked ( $99 \pm 1 \%, 8$ cells) by extracellular application of methyllycaconitine (MLA; $10-20 \mathrm{nM})$, a potent and selective antagonist of $\alpha 7$-containing nAChRs (Fig. 2A). However, these responses were not affected (the amplitude was reduced by $2 \pm 2 \%$; three cells) by dihydro$\beta$-erythroidine (DH $\beta \mathrm{E} ; 10 \mu \mathrm{M}$ ) (Fig. $2 \mathrm{~B}$ ), a competitive antagonist of the non- $\alpha 7$ nAChRs. Therefore, under our recording conditions, uncaging pulses of carbachol preferentially activated $\alpha 7$ containing $\mathrm{nAChRs}$ in rat CA1 stratum radiatum hippocampal interneurons. Sometimes we observed more slowly activating responses that were not completely blocked by MLA and were sensitive to $\mathrm{DH} \beta \mathrm{E}$ (data not shown), which were likely mediated by the non- $\alpha 7$ nAChRs. However, because of the infrequent occurrence and small amplitude of these slow currents, they were extremely difficult to quantify. Thus, for the present study, we focused solely on the $\alpha 7$-containing nAChRs.

\section{Distribution of functional $\alpha$-containing nAChRs on interneurons}

The spatial resolution $(\sim 7 \mu \mathrm{m})$ of our technique allowed us to map the distribution of functional $\alpha 7$-containing receptors on interneurons and pyramidal cells. To do this, we moved the uncaging laser spot along different regions of the soma and dendrites. Figure $3 A$ shows a three-dimensional (3D) reconstructed confocal image of a regular-spiking interneuron (see Materials and Methods and below) and the positions at which these receptors were studied. Although it is clear that the largest response was generated at the cell body, responses were also observed on each of the three dendritic processes tested, with an amplitude that appears to decrease with distance from the soma (see below). To determine the functional profile of the interneurons studied, we have investigated the action potential firing properties of some of the neurons from which we recorded. All of the interneurons analyzed for firing properties ( $n=9$ cells) had a regular-spiking action potential firing profile (the average firing rate was $20 \pm 3$ 


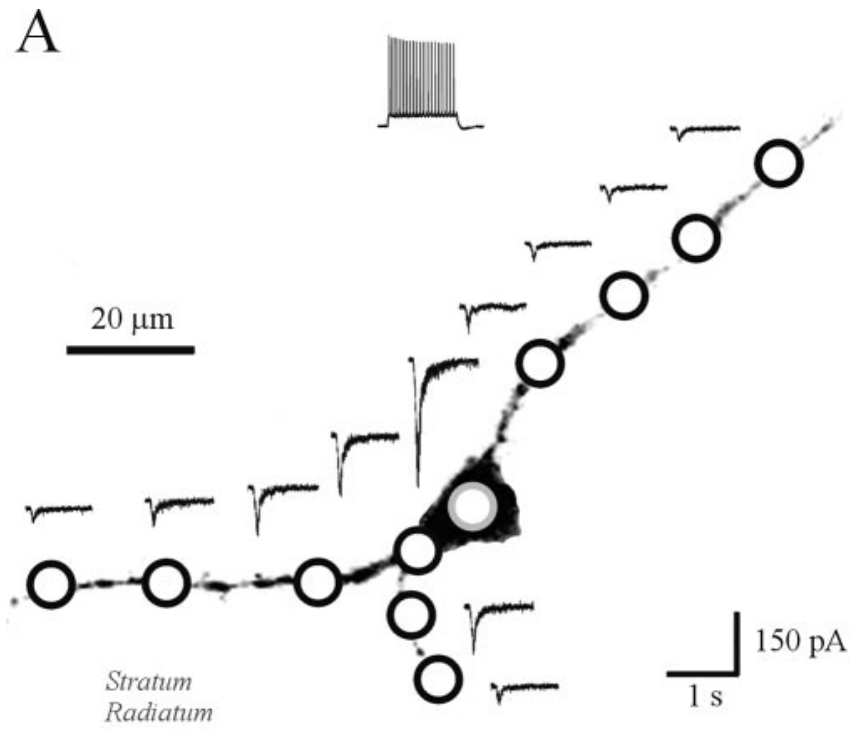

B

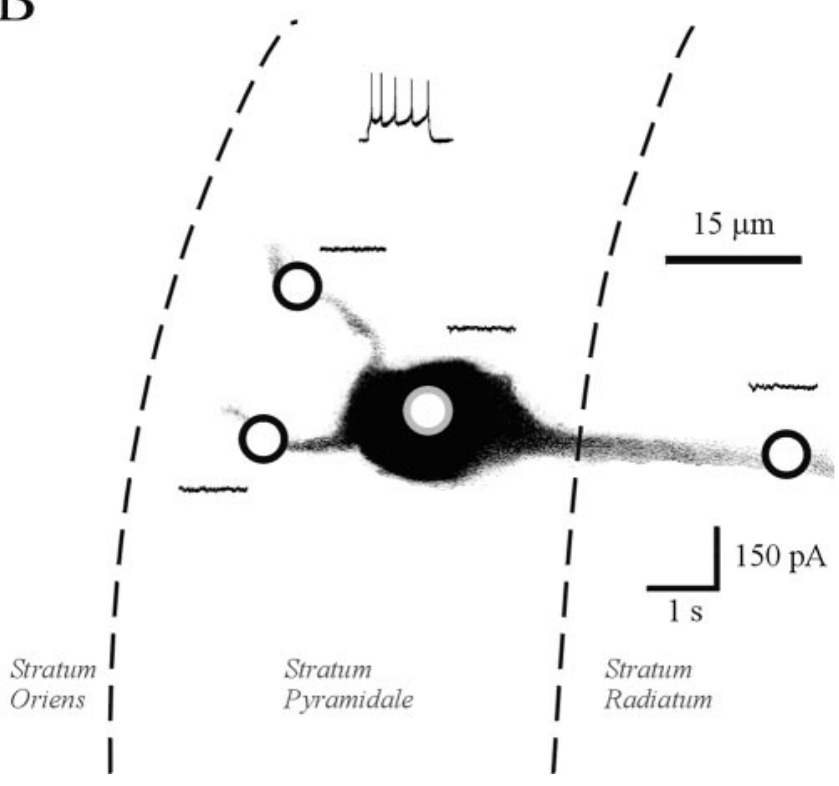

Figure 3. Distribution of functional nAChRs on hippocampal interneurons and lack of response on pyramidal neurons. Carbachol uncaging responses evoked by $25 \mathrm{msec}$ UV pulses on the soma and dendrites of a CA1 stratum radiatum interneuron $(A)$ and a CA1 pyramidal neuron $(B)$. The current traces are shown next to their respective uncaging positions, indicated by the circles. The insets illustrate the spike firing properties of the respective neurons. The duration of the depolarizing step is $1 \mathrm{sec}$.

$\mathrm{Hz}$ ) (Fig. $3 A$, inset); none of the cells showed typical fast-spiking properties previously observed for other CA1 interneurons (Sudweeks et al., 2002).

The decay of currents induced by carbachol uncaging pulses was best fit with a two-exponential function, whether responses were obtained from the soma or the dendrites. For the soma in 19 cells, the fast time constant of decay averaged $23 \pm 4 \mathrm{msec}$ and comprised $77 \pm 19 \%$ of the fit, whereas the slow time constant of decay averaged $200 \pm 20 \mathrm{msec}$. For dendritic responses, there was no significant differences $(p>0.05)$ in the kinetics of decay; the fast time constant of decay averaged $30 \pm 6 \mathrm{msec}$ and comprised $77 \pm 17 \%$ of the fit, whereas the slow time constant of decay averaged $240 \pm 25 \mathrm{msec}$.

In contrast to the results from interneurons, we were never able to induce responses by the photolysis of caged carbachol onto CA1 pyramidal neurons (Fig. $3 B$ ), either at the soma or at various points along the dendritic tree ( $n=6$ cells); currentclamp tests revealed normal spike firing properties expected of pyramidal neurons (Fig. 3B, inset). These data are consistent with our previous observations in which we could not induce any nAChR-mediated responses from these cells in response to the exogenous application of ACh (Jones and Yakel, 1997; Sudweeks and Yakel, 2000).

As mentioned above, it appears that the density of functional $\alpha 7$-containing receptors was highest at the soma. To examine this issue in more detail, we quantified the dependence of current amplitude on distance from the soma and compared it to the distribution of responses produced by local photolysis of glutamate. In Figure $4 A$, carbachol and glutamate uncaging-induced currents were elicited by uncaging at four different positions (one somatic and three dendritic) on the same interneuron. Whereas the amplitude for carbachol was much larger at the soma (trace 3 ) as compared with dendritic locations (in particular, trace 1), the difference in amplitude for glutamate responses was much less pronounced. The relative amplitude of responses obtained from this cell is plotted versus distance from soma in Figure $4 B$. We normalized the amplitudes at dendritic locations to the amplitude at the soma and plotted these values versus distance from the soma for a number of cells tested with carbachol (Fig. 4C) (19 cells) and/or glutamate (Fig. 4D) (13 cells). The resulting dependence for carbachol-induced currents was well fit with a singleexponential function with a length constant of $29 \mu \mathrm{m}$. The distance dependence of the amplitudes of glutamate-induced currents required fitting with a two-exponential function, which yielded length constants of 6 and $1000 \mu \mathrm{m}$. Therefore on average, there were virtually no $(<10 \%)$ nAChR-mediated responses at dendritic locations $>70 \mu \mathrm{m}$ from the soma, whereas for glutamate, the responses elicited at the same distance from soma were on average $40 \%$ of the somatic ones (Fig. 4). These data suggest that in these interneurons, the highest density of functional $\alpha 7$ containing receptors is found at the soma and perisomatic regions, and that the density significantly decreases with distance from the soma.

\section{Kinetics of desensitization and recovery of $\alpha 7$-containing nAChRs}

It is well known that $\alpha 7$-containing nAChRs rapidly desensitize, with a time course of desensitization onset ranging from $\sim 8 \mathrm{msec}$ up to $\sim 1 \mathrm{sec}$, depending on the agonist, concentration, and preparation (Bertrand et al., 1993; Séguéla et al., 1993; Khiroug et al., 2002; Quick and Lester, 2002). For cultured hippocampal neurons, $\alpha 7$-containing nAChR-mediated responses (activated by ACh with fast application techniques) peaked in $\sim 10 \mathrm{msec}$ and desensitized with a time course for the fast decay phase ranging from $\sim 8-30$ msec (Zorumski et al., 1992; Alkondon and Albuquerque, 1993; Liu et al., 2001a,b).

To quantify the rate of onset of desensitization by means of carbachol uncaging would have required us to use much longer uncaging pulses (i.e., $>200 \mathrm{msec}$ ). This was not feasible under the present experimental conditions because large amounts of carbachol uncaged by long UV pulses would gradually diffuse to more distant segments of the membrane and activate remote nAChRs. Therefore, we used pressure application to assess the rate of onset of desensitization. When maximal doses of either ACh $(2 \mathrm{~mm})$ or carbachol $(4 \mathrm{~mm})$ were pressure applied, the currents reached peak amplitudes averaging $(n=4$ cells $) 401 \pm$ 
$68 \mathrm{pA}$ for ACh and $365 \pm 66 \mathrm{pA}$ for carbachol, and desensitized with a biphasic time course. For ACh, the fast time constant of decay averaged $117 \pm 21 \mathrm{msec}$ and comprised $68 \pm 13 \%$ of the fit, and the slow time constant of decay averaged $1.29 \pm$ $0.13 \mathrm{sec}$. For carbachol, these values were, respectively, $117 \pm 10 \mathrm{msec}$ (comprising $63 \pm 16 \%$ of the fit) and $1.27 \pm 0.08 \mathrm{sec}$. Therefore, these results suggest that the rate of desensitization of these $\alpha 7$ containing nAChRs in acute slices is slower than that for dissociated neurons in culture.

To study the process of receptor recovery from desensitization, we used brief (15-25 msec) photolysis of caged carbachol and applied a second carbachol uncaging pulse (of the same duration and UV power) soon after (i.e., between 3-30 sec) the first one (Fig. 5A). We found that the amplitude of the second response was dramatically reduced because of receptor desensitization. Plotting the relative amplitude of the second response (normalized to the amplitude of the first response) versus the time interval between these two pulses yielded the rate of recovery from desensitization of $23 \pm 4 \sec (n=10$ cells $)$.

Because it was previously shown that the addition of intracellular $\mathrm{Ca}^{2+}$ chelators through the patch pipette increased the rate of recovery from desensitization for nAChRs in rat chromaffin cells (Khiroug et al., 1997), we tested whether the $n A C h R$ recovery from desensitization in hippocampal interneurons might be similarly regulated. When we buffered the cytoplasmic calcium concentration $\left(\left[\mathrm{Ca}^{2+}\right]_{\mathrm{i}}\right)$ to very low levels by adding a high dose (20 $\mathrm{mm}$ ) of the calcium chelator BAPTA to the patch pipette solution, the recovery from desensitization was significantly faster $(p<$ $0.01)$, now with a time constant of $6.2 \pm 2 \mathrm{sec}$

$(n=7)$ (Fig. $5 B)$. Importantly, the average amplitude of the first current was not significantly different $(p>0.05)$ between control and BAPTA-containing cells $(n=10)$, indicating that the difference in recovery from desensitization was not related to different numbers of functional receptors activated under these two conditions. Therefore, it appears that a calcium-dependent mechanism regulates the rate of $n A C h R$ recovery from desensitization in CA1 hippocampal interneurons.

\section{Activation of $\alpha 7$-containing nAChRs increases $\left[\mathrm{Ca}^{2+}\right]_{\mathrm{i}}$}

Using the carbachol uncaging and confocal imaging system to measure cytoplasmic $\mathrm{Ca}^{2+}$ levels $\left(\left[\mathrm{Ca}^{2+}\right]_{\mathrm{i}}\right)$, we could only observe very small $\mathrm{Ca}^{2+}$ signals that were difficult to quantify (data not shown). We hypothesized that the relatively small average amplitude $(\sim 300 \mathrm{pA})$ and brief duration of carbachol uncaging currents might explain why the accompanying $\mathrm{Ca}^{2+}$ influx through the nAChRs was below the detection level. Induction of larger amplitude responses required the pressure application of nAChR agonists to the whole cell. However, this causes some
B

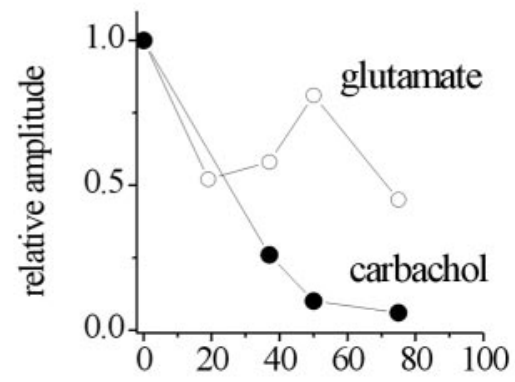

dendrite distance, $\mu \mathrm{m}$
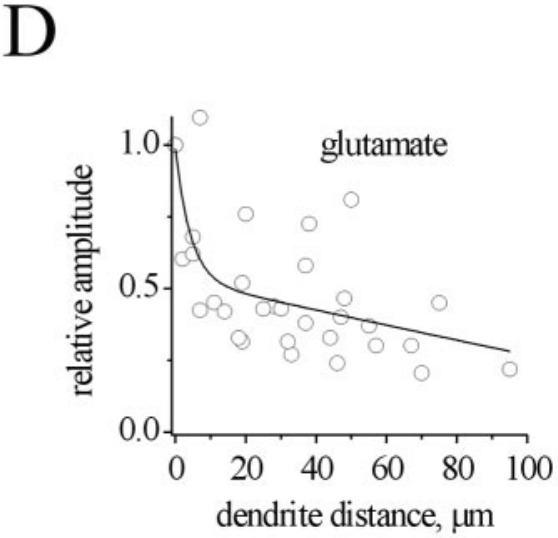

Figure 4. Comparison of distribution of functional $n A C h R s$ and glutamate receptors on hippocampal interneurons. $A$, Repre( circles) for the interneuron shown in $A$. Distribution of carbachol $(C)$ and glutamate $(D)$ responses along the dendrites (relative to the soma) from many cells: 19 interneurons for carbachol and 13 interneurons for glutamate. See Results for fitting procedures.

movement of the cell soma, which compromises the nonratiometric fluo-4-based $\mathrm{Ca}^{2+}$ measurements when confocal microscopy is used. Therefore, changes in $\left[\mathrm{Ca}^{2+}\right]_{\mathrm{i}}$ levels were assessed with the conventional fura-2 fluorescent imaging technique and a digital camera (see Materials and Methods).

In the 25 interneurons examined, the activation of nAChRs by the pressure application of either ACh or carbachol induced currents that resulted in significant increases in $\left[\mathrm{Ca}^{2+}\right]_{\mathrm{i}}$ (Fig. 6), up to a maximum increase of $20 \mathrm{~nm}$ (average increase was $7 \pm 1 \mathrm{~nm}$ ) above the baseline $\left[\mathrm{Ca}^{2+}\right]_{\mathrm{i}}$ of $59 \pm 5 \mathrm{nM}$; there was no significant difference in the peak amplitude of either current responses or $\mathrm{Ca}^{2+}$ signals to ACh or carbachol (seven cells). For the representative cell shown in Figure $6 A$, most of the current was carried by the $\alpha 7$-containing nAChRs because it was sensitive to MLA. The amplitude of the $\mathrm{Ca}^{2+}$ signals caused by the activation of nAChRs was linearly related with the amplitude of current response (which averaged $551 \pm 62 \mathrm{pA}$ ) (Fig. 6B). These data indicate that the native $\alpha 7$-containing nAChRs in acute slices are significantly $\mathrm{Ca}^{2+}$-permeable. 
A

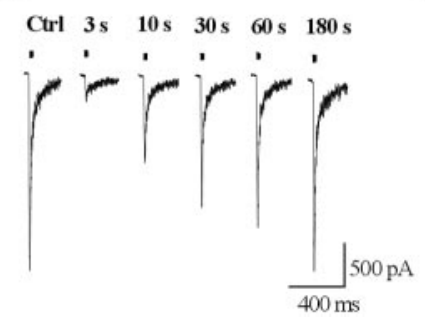

B

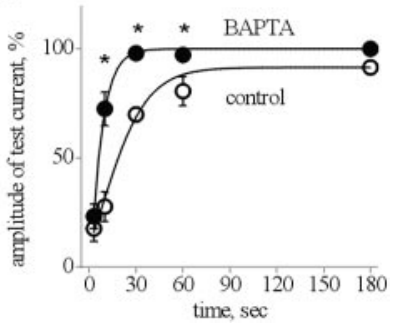

Figure 5. Time course for the recovery of $n A C h R$ desensitization is $\mathrm{Ca}^{2+}$-dependent. $A$, Representative traces of carbachol responses ( 25 msec UV pulses) at various intervals (3-180 $\mathrm{sec}$ ) between the control response (time 0 ) and the test pulse. $B$, Plot of the relative current amplitude (normalized to the amplitude of the control response) versus time interval in the absence (i.e., control conditions; open circles) and presence of BAPTA ( $20 \mathrm{~mm}$; filled circles). The asterisks denote a significant difference $(p<0.05)$ compared with control.

\section{Discussion}

The main goal of the present study was to study the distribution and $\mathrm{Ca}^{2+}$ regulation of functional nAChRs on rat hippocampal CA1 stratum radiatum interneurons and pyramidal cells, which represent the two major classes of neurons in the hippocampal network. Using the local photolysis of caged carbachol to activate nAChRs, we show that functional receptors are preferentially expressed on interneurons, but not on pyramidal cells, consistent with previous results from our lab and others (see below). The $\alpha 7$-containing nAChRs were the predominant subtype of nAChRs expressed on these interneurons and were located primarily at the soma and proximal dendrites (i.e., $<70 \mu \mathrm{m}$ from the soma). In addition, these $\alpha 7$-containing receptors were significantly $\mathrm{Ca}^{2+}$-permeable because their activation increased $\left[\mathrm{Ca}^{2+}\right]_{\mathrm{i}}$, and the rate at which these channels recovered from desensitization was much faster in cells dialyzed with the calcium chelator BAPTA.

In the rat hippocampus, interneurons receive cholinergic input from the MSDB of the basal forebrain (Frotscher and Léránth, 1985; Woolf, 1991), as well as from intrinsic cholinergic interneurons (Matthews et al., 1987; Cobb et al., 1999). Diverse subtypes of nAChRs are expressed in the hippocampus, including fast-desensitizing $\alpha 7$-containing and slow-desensitizing non- $\alpha 7$ receptors (Alkondon and Albuquerque, 1993; Alkondon et al., 1997; Jones and Yakel, 1997; Frazier et al., 1998a; McQuiston and Madison, 1999; Ji and Dani, 2000). Many groups have found that interneurons in rat hippocampal slices preferentially express functional nAChRs (Jones and Yakel, 1997; Alkondon et al., 1998; Frazier et al., 1998a; McQuiston and Madison, 1999; Ji and Dani, 2000), however others have reported expression on pyramidal neurons as well (Hefft et al., 1999; Ji et al., 2001). Although nAChRs are preferentially expressed in interneurons, our previous single-cell RT-PCR studies have shown that pyramidal cells possess low, but detectable, levels of mRNA encoding various nAChR subunits, including the $\alpha 7$ subunit (Sudweeks and Yakel, 2000). The reason for this discrepancy is currently unknown, however a potential explanation may lie in the rapid kinetics of desensitization of $\alpha 7$-containing nAChRs. By using the fast kinetics of local photolysis of caged carbachol $(\sim 100 \mu \mathrm{sec}$; Niu and Hess, 1993), any attenuation caused by rapid desensitization can be significantly reduced or eliminated. We induced uncaging responses with amplitudes of up to $1 \mathrm{nA}$ from small patches $(7 \mu \mathrm{m})$ of membrane. Assuming a single channel conductance value of $38 \mathrm{pS}$ for these $\alpha 7$-containing nAChRs (Shao and Yakel, 2000), this indicates that $\sim 500$ channels were activated in this particular patch. Our lack of detection of responses from pyramidal neurons suggests a much lower density of functional nAChRs.

Immunohistochemical staining, EM analysis, and the use of fluorescently labeled $\alpha$-bungarotoxin, has revealed the presence of $\alpha 7$-containing nAChRs in most regions of the hippocampus and/or cultured hippocampal neurons, both on soma and dendrites, and at most synapses, including both GABAergic and glutamatergic ones (Dominguez del Toro et al., 1994; Barrantes et al., 1995; Zarei et al., 1999; Fabian-Fine et al., 2001; Kawai et al., 2002). The reason why immunostaining for nAChRs was observed for both interneurons and pyramidal neurons, whereas our functional assay revealed functional nAChRs on interneurons only, remains to be determined. In addition, our method did not allow us to determine whether the functional receptors that we have studied were located within postsynaptic densities or at extrasynaptic sites. Previous reports have shown that $\alpha 7$ containing $\mathrm{nAChRs}$ are located at postsynaptic sites on hippocampal interneurons and mediate fast cholinergic excitatory synaptic transmission (Frazier et al., 1998b; Alkondon et al., 1998). However, these receptors might also be located and function extrasynaptically. For example, there is evidence in the hippocampus that most of the cholinergic action may be mediated by nonsynaptic, diffuse, so-called "volume transmission" (Umbriaco et al., 1995). In addition, in chick parasympathetic ciliary ganglion neurons, $\alpha 7$-containing nAChRs are excluded from the synapse and localize perisynaptically (Shoop et al., 2001; Brumwell et al., 2002). Nevertheless, the strategic localization of functional $\alpha 7$-containing $\mathrm{nAChRs}$ to the perisomatic region of rat hippocampal CA1 stratum radiatum interneurons may result in their ability to better control the excitatory drive to these interneurons.

The distribution of $\mathrm{nAChRs}$ was significantly different from that of ionotropic glutamate receptors. While the amplitude of currents induced by carbachol uncaging decayed with distance along the dendrites (becoming nearly undetectable beyond $\sim 70$ $\mu \mathrm{m}$ ) (Fig. 4C), the gradient of amplitudes of glutamate-induced currents was much smaller (Fig. $4 D$ ). The latter pattern is likely to reflect an increase in glutamate receptor density with distance from soma (when taking into account the decrease in dendritic diameter), which has previously been reported for hippocampal CA1 interneurons (Pettit and Augustine, 2000) and pyramidal cells (Pettit and Augustine, 2000; Andrasfalvy and Magee, 2001; Smith et al., 2003). This increase in glutamate receptor density with distance from the soma has been suggested to compensate for the attenuation of dendritic signals caused by cable properties (Magee and Cook, 2000).

The function of nAChRs has been linked to specific cognitive processes in humans and animal models (Levin, 2002), and dysfunctions in these receptors may be involved in various neurodegenerative diseases (Jones et al., 1999), such as Alzheimer's disease (Pettit et al., 2001; Liu et al., 2001b). Although clear evidence indicates that $\mathrm{nAChRs}$ can directly regulate synaptic plasticity in the hippocampus (Hunter et al., 1994; Fujii and Sumikawa, 2001; Ji et al., 2001; McGehee, 2002), the cellular mechanisms involved are not fully understood, but likely involve the important second messenger, $\mathrm{Ca}^{2+} \cdot \mathrm{Ca}^{2+}$ can activate and regulate a variety of signal transduction cascades and plays a key role in the shortterm and long-term regulation of nAChRs (Quick and Lester, 2002). In heterologous expression systems, homomeric $\alpha 7$ nAChRs have a high permeability to $\mathrm{Ca}^{2+}$ (Bertrand et al., 1993; Séguéla et al., 1993), as do native $\alpha 7$-containing nAChRs in cultured hippocampal neurons (Castro and Albuquerque, 1995). We have now shown, for the first time, that the activation of these 


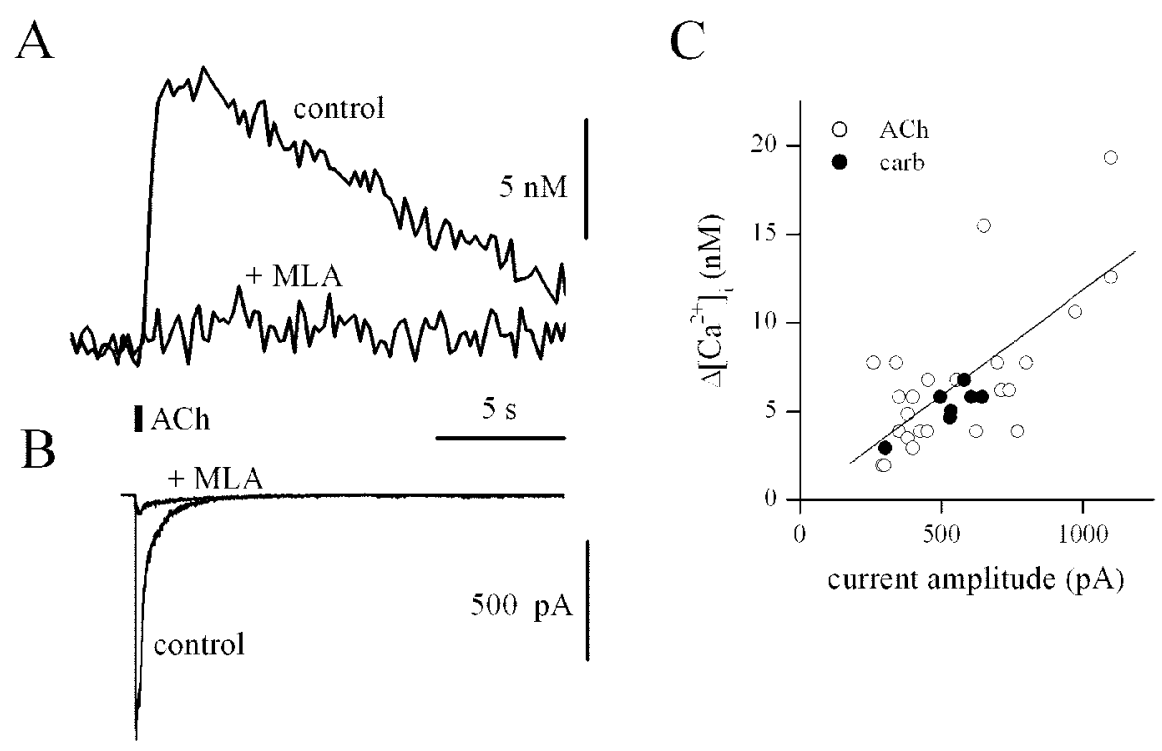

Figure 6. Activation of $\alpha 7$-containing $n A C h R s$ increases $\left[\mathrm{Ca}^{2+}\right]_{\mathrm{i}}$. A, In a voltage-clamped interneuron, activation of $n A C h R s$ by pressure application of $\mathrm{ACh}(2 \mathrm{mM})$ or carbachol $(4 \mathrm{~mm})$ significantly increased $\left[\mathrm{Ca}^{2+}\right]_{\mathrm{i}}$. The corresponding current trace is shown in $B$. Both the $\mathrm{Ca}^{2+}$ signal and current response were blocked by MLA (10 nM), suggesting the involvement of the $\alpha 7$-containing $n A C h R s . C$, Plot of amplitude of $\mathrm{Ca}^{2+}$ signal for responses produced by $\mathrm{ACh}$ (open circles) and carbachol (filled circles) versus that of the current response for each of 25 interneurons examined. The data are well fit with a linear function.

receptors in hippocampal interneurons in the slice significantly increases $\left[\mathrm{Ca}^{2+}\right]_{\mathrm{i}}$. On presynaptic terminals in the hippocampus, Gray et al. (1996) have found that activation of $\alpha 7$-containing nAChRs increased intraterminal $\mathrm{Ca}^{2+}$ levels and facilitated transmitter release, however others have failed to observe this effect (Vogt and Regehr, 2001). Native neuronal nAChRs have also been shown to be $\mathrm{Ca}^{2+}$-permeable in isolated rat medial habenular nucleus neurons (Mulle et al., 1992), in mouse substantia nigra pars compacta neurons in the slice (Tsuneki et al., 2000), and in chick ciliary ganglion neurons (Shoop et al., 2001).

The $\alpha 7$-containing nAChRs undergo rapid desensitization, although the physiological relevance of this phenomenon remains unclear (Quick and Lester, 2002). The slight decay of responses during $25 \mathrm{msec}$ carbachol uncaging pulses and rate of desensitization to pressure-applied ACh and carbachol $(>100$ $\mathrm{msec}$ ) indicates that the onset of desensitization of $\alpha 7$-containing $\mathrm{nAChRs}$ for interneurons in acute hippocampal slices is slower than for responses from cultured hippocampal neurons (i.e., 8-30 msec; Zorumski et al., 1992; Alkondon and Albuquerque, 1993; Liu et al., 2001a,b), and that there is little to no desensitization at the peak of uncaging pulses that would significantly attenuate response amplitudes. Within a few seconds after the uncaging pulse, nAChRs were strongly desensitized when a second pulse was applied (Fig. 5). Under control conditions, the rate of recovery from desensitization occurred with a time constant of 23 sec. However, when $\left[\mathrm{Ca}^{2+}\right]_{\mathrm{i}}$ was strongly buffered with BAPTA, the rate of recovery was much faster $(6 \mathrm{sec})$. This is consistent with our previous studies in rat chromaffin cells showing that the recovery of nAChRs from desensitization was slower when $\left[\mathrm{Ca}^{2+}\right]_{\mathrm{i}}$ elevation lasted longer (Khiroug et al., 1997, 1998). The $\mathrm{nAChRs}$ in these cells comprise heterologous assemblies of $\alpha 3, \alpha 5$, and $\beta 4$ subunits (Criado et al., 1992; Campos-Caro et al., 1997), as well as a distinct homomeric $\alpha 7$ subtype (Garcia-Guzman et al., 1994). The $\mathrm{Ca}^{2+}$ dependence of recovery from desensitization of nAChRs in chromaffin cells likely did not involve the $\alpha 7$ subtype because $\alpha$-bungarotoxin was ineffective at either blocking inward current or $\left[\mathrm{Ca}^{2+}\right]_{\mathrm{i}}$ responses (Khiroug et al., 1997). In contrast, for

\section{References} 265:1455-1473. Ther 283:1396-1411. USA 90:6971-6975. 68:516-524. 32:855-865. $\alpha 4 \beta 2$ nAChRs expressed in Xenopus oocytes, the elevation of $\left[\mathrm{Ca}^{2+}\right]_{\mathrm{i}}$ and subsequent activation of PKC promotes the recovery from desensitization (Fenster et al., 1997; 1999; Quick and Lester, 2002).

In chick ciliary ganglion neurons, the activation of $\alpha 7$-containing nAChRs induces $\mathrm{Ca}^{2+}$ transients confined to the spines (Shoop et al., 2001), which activates the CaMK and MAPK pathways, leading to activation of the transcription factor CREB and gene expression (Chang and Berg, 2001). Furthermore, the function of these receptors runs down with time in a $\mathrm{Ca}^{2+}$-dependent manner, and this rundown is enhanced by inhibition of the $\mathrm{Ca}^{2+}$-dependent phosphatase calcineurin and prevented by block of the $\mathrm{Ca}^{2+}$-dependent kinase CaMKII (Liu and Berg, 1999). Therefore, despite the extrasynaptic distribution of these $\alpha 7$-containing $\mathrm{nAChRs}$, they have important $\mathrm{Ca}^{2+}$ dependent signaling functions at the synapse. Thus, $\mathrm{Ca}^{2+}$ is a strong modulator of the function of both $\alpha 7$ - and non- $\alpha 7$ containing nAChRs and can act through a variety of signal transduction cascades.

Alkondon M, Albuquerque EX (1993) Diversity of nicotinic acetylcholine receptors in rat hippocampal neurons. I. Pharmacological and functional evidence for distinct structural subtypes. J Pharmacol Exp Ther

Alkondon M, Pereira EF, Barbosa CT, Albuquerque EX (1997) Neuronal nicotinic acetylcholine receptor activation modulates $\gamma$-aminobutyric acid release from CA1 neurons of rat hippocampal slices. J Pharmacol Exp

Alkondon M, Pereira EF, Albuquerque EX (1998) $\alpha$-bungarotoxin- and methyllycaconitine-sensitive nicotinic receptors mediate fast synaptic transmission in interneurons of rat hippocampal slices. Brain Res 810:257-263.

Andrasfalvy BK, Magee JC (2001) Distance-dependent increase in AMPA receptor number in the dendrites of adult hippocampal CA1 pyramidal neurons. J Neurosci 21:9151-9159.

Barrantes GE, Rogers AT, Lindstrom J, Wonnacott S (1995) $\alpha$-Bungarotoxin binding sites in rat hippocampal and cortical cultures: initial characterisation, colocalisation with $\alpha 7$ subunits and upregulation by chronic nicotine treatment. Brain Res 672:228-236.

Berg DK, Conroy WG (2002) Nicotinic $\alpha 7$ receptors: synaptic options and downstream signaling in neurons. J Neurobiol 53:512-523.

Bertrand D, Galzi JL, Devillers-Thiéry A, Bertrand S, Changeux J-P (1993) Mutations at two distinct sites within the channel domain M2 alter calcium permeability of neuronal $\alpha 7$ nicotinic receptor. Proc Natl Acad Sci

Brumwell CL, Johnson JL, Jacob MH (2002) Extrasynaptic $\alpha 7$-nicotinic acetylcholine receptor expression in developing neurons is regulated by inputs, targets, and activity. J Neurosci 22:8101-8109.

Campos-Caro A, Smillie FI, Dominguez del Toro E, Rovira JC, VicenteAgullo F, Chapuli J, Juiz JM, Sala S, Sala F, Ballesta JJ, Criado M (1997) Neuronal nicotinic acetylcholine receptors on bovine chromaffin cells: cloning, expression, and genomic organization of receptor subunits. J Neurochem 68:488-497.

Castro NG, Albuquerque EX (1995) $\alpha$-Bungarotoxin-sensitive hippocampal nicotinic receptor channel has a high calcium permeability. Biophys J

Chang KT, Berg DK (2001) Voltage-gated channels block nicotinic regulation of CREB phosphorylation and gene expression in neurons. Neuron

Cobb SR, Bulters DO, Suchak S, Riedel G, Morris RG, Davies CH (1999) Activation of nicotinic acetylcholine receptors patterns network activity in the rodent hippocampus. J Physiol (Lond) 518:131-140. 
Criado M, Alamo L, Navarro A (1992) Primary structure of an agonist binding subunit of the nicotinic acetylcholine receptor from bovine adrenal chromaffin cells. Neurochem Res 17:281-287.

Dominguez del Toro E, Juiz JM, Peng X, Lindstrom J, Criado M (1994) Immunocytochemical localization of the $\alpha 7$ subunit of the nicotinic acetylcholine receptor in the rat central nervous system. J Comp Neurol 349:325-342.

Fabian-Fine R, Skehel P, Errington ML, Davies HA, Sher E, Stewart MG, Fine A (2001) Ultrastructural distribution of the $\alpha 7$ nicotinic acetylcholine receptor subunit in rat hippocampus. J Neurosci 21:7993-8003.

Fenster CP, Rains MF, Noerager B, Quick MW, Lester RA (1997) Influence of subunit composition on desensitization of neuronal acetylcholine receptors at low concentrations of nicotine. J Neurosci 17:5747-5759.

Fenster CP, Beckman ML, Parker JC, Sheffield EB, Whitworth TL, Quick MW, Lester RA (1999) Regulation of $\alpha 4 \beta 2$ nicotinic receptor desensitization by calcium and protein kinase C. Mol Pharmacol 55:432-443.

Frazier CJ, Rollins YD, Breese CR, Leonard S, Freedman R, Dunwiddie TV (1998a) Acetylcholine activates an alpha-bungarotoxin-sensitive nicotinic current in rat hippocampal interneurons, but not pyramidal cells. J Neurosci 18:1187-1195.

Frazier CJ, Buhler AV, Weiner JL, Dunwiddie TV (1998b) Synaptic potentials mediated via alpha-bungarotoxin-sensitive nicotinic acetylcholine receptors in rat hippocampal interneurons. J Neurosci 18:8228-8235.

Frotscher M, Léránth C (1985) Cholinergic innervation of the rat hippocampus as revealed by choline acetyltransferase immunocytochemistry: a combined light and electron microscopic study. J Comp Neurol 239:237-246.

Fujii S, Sumikawa K (2001) Nicotine accelerates reversal of long-term potentiation and enhances long-term depression in the rat hippocampal CA1 region. Brain Res 894:340-346.

Garcia-Guzman M, Sala F, Sala S, Campos-Caro A, Criado M (1994) Role of two acetylcholine receptor subunit domains in homomer formation and intersubunit recognition, as revealed by $\alpha 3$ and $\alpha 7$ subunit chimeras. Biochemistry 33:15198-15203.

Gray R, Rajan AS, Radcliffe KA, Yakehiro M, Dani JA (1996) Hippocampal synaptic transmission enhanced by low concentrations of nicotine. Nature 383:713-716.

Hefft S, Hulo S, Bertrand D, Muller D (1999) Synaptic transmission at nicotinic acetylcholine receptors in rat hippocampal organotypic cultures and slices. J Physiol (Lond) 515:769-776.

Hunter BE, de Fiebre CM, Papke RL, Kem WR, Meyer EM (1994) A novel nicotinic agonist facilitates induction of long-term potentiation in the rat hippocampus. Neurosci Lett 168:130-134.

Ji D, Dani JA (2000) Inhibition and disinhibition of pyramidal neurons by activation of nicotinic receptors on hippocampal interneurons. J Neurophysiol 83:2682-2690.

Ji D, Lape R, Dani JA (2001) Timing and location of nicotinic activity enhances or depresses hippocampal synaptic plasticity. Neuron 31:131-141.

Jones S, Yakel JL (1997) Functional nicotinic ACh receptors on interneurones in the rat hippocampus. J Physiol (Lond) 504:603-610.

Jones S, Sudweeks S, Yakel JL (1999) Nicotinic receptors in the brain: correlating physiology with function. Trends Neurosci 22:555-561.

Kawai H, Zago W, Berg DK (2002) Nicotinic $\alpha 7$ receptor clusters on hippocampal GABAergic neurons: regulation by synaptic activity and neurotrophins. J Neurosci 22:7903-7912.

Khiroug L, Giniatullin R, Sokolova E, Talantova M, Nistri A (1997) Imaging of intracellular calcium during desensitization of nicotinic acetylcholine receptors of rat chromaffin cells. Br J Pharmacol 122:1323-1332.

Khiroug L, Sokolova E, Giniatullin R, Afzalov R, Nistri A (1998) Recovery from desensitization of neuronal nicotinic acetylcholine receptors of rat chromaffin cells is modulated by intracellular calcium through distinct second messengers. J Neurosci 18:2458-2466.

Khiroug SS, Harkness PC, Lamb PW, Sudweeks SN, Khiroug L, Millar NS, Yakel JL (2002) Rat nicotinic ACh receptor $\alpha 7$ and $\beta 2$ subunits coassemble to form functional heteromeric nicotinic receptor channels. J Physiol (Lond) 540:425-434.

Levin ED (2002) Nicotinic receptor subtypes and cognitive function. J Neurobiol 53:633-640.

Liu Q, Berg DK (1999) Actin filaments and the opposing actions of CaM kinase II and calcineurin in regulating $\alpha 7$-containing nicotinic receptors on chick ciliary ganglion neurons. J Neurosci 19:10280-10288.

Liu Y, Ford B, Mann MA, Fischbach GD (2001a) Neuregulins increase $\alpha 7$ nicotinic acetylcholine receptors and enhance excitatory synaptic transmission in GABAergic interneurons of the hippocampus. J Neurosci 21:5660-5669.

Liu Q, Kawai H, Berg DK (2001b) $\beta$-Amyloid peptide blocks the response of $\alpha 7$-containing nicotinic receptors on hippocampal neurons. Proc Natl Acad Sci USA 98:4734-4739.

Magee JC, Cook EP (2000) Somatic EPSP amplitude is independent of synapse location in hippocampal pyramidal neurons. Nat Neurosci 3:895-903.

Matthews DA, Salvaterra PM, Crawford GD, Houser CR, Vaughn JE (1987) An immunocytochemical study of choline acetyltransferase-containing neurons and axon terminals in normal and partially deafferented hippocampal formation. Brain Res 402:30-43.

McGehee DS, Role LW (1995) Physiological diversity of nicotinic acetylcholine receptors expressed by vertebrate neurons. Annual Rev Physiol 57:521-546.

McGehee DS (2002) Nicotinic receptors and hippocampal synaptic plasticity it's all in the timing. Trends Neurosci 25:171-172.

McQuiston AR, Madison DV (1999) Nicotinic receptor activation excites distinct subtypes of interneurons in the rat hippocampus. J Neurosci 19:2887-2896.

Mulle C, Choquet D, Korn H, Changeux J-P (1992) Calcium influx through nicotinic receptor in rat central neurons: its relevance to cellular regulation. Neuron 8:135-143.

Niu L, Hess GP (1993) An acetylcholine receptor regulatory site in BC3H1 cells: characterized by laser-pulse photolysis in the microsecond-tomillisecond time region. Biochemistry 32:3831-3835.

Pettit DL, Augustine GJ (2000) Distribution of functional glutamate and GABA receptors on hippocampal pyramidal cells and interneurons. J Neurophysiol 84:28-38.

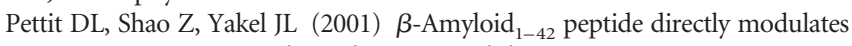
nicotinic receptors in the rat hippocampal slice. J Neurosci 21:RC120.

Quick MW, Lester RA (2002) Desensitization of neuronal nicotinic receptors. J Neurobiol 53:457-478.

Séguéla P, Wadiche J, Dineley-Miller K, Dani JA, Patrick JW (1993) Molecular cloning, functional properties, and distribution of rat brain $\alpha 7$ : a nicotinic cation channel highly permeable to calcium. J Neurosci 13:596-604.

Shao Z, Yakel JL (2000) Single channel properties of neuronal nicotinic ACh receptors in stratum radiatum interneurons of rat hippocampal slices. J Physiol (Lond) 527:507-513.

Shoop RD, Chang KT, Ellisman MH, Berg DK (2001) Synaptically driven calcium transients via nicotinic receptors on somatic spines. J Neurosci 21:771-781.

Smith MA, Ellis-Davies GC, Magee JC (2003) Mechanism of the distancedependent scaling of Schaffer collateral synapses in rat CA1 pyramidal neurons. J Physiol (Lond) 548:245-258.

Sudweeks SN, Yakel JL (2000) Functional and molecular characterization of neuronal nicotinic ACh receptors in rat CA1 hippocampal neurons. J Physiol (Lond) 527:515-528.

Sudweeks SN, van Hooft JA, Yakel JL (2002) Serotonin 5-HT 3 receptors in rat CA1 hippocampal interneurons: functional and molecular characterization. J Physiol (Lond) 544:715-726.

Tsuneki H, Klink R, Léna C, Korn H, Changeux J-P (2000) Calcium mobilization elicited by two types of nicotinic acetylcholine receptors in mouse substantia nigra pars compacta. Eur J Neurosci 12:2475-2485.

Umbriaco D, Garcia S, Beaulieu C, Descarries L (1995) Relational features of acetylcholine, noradrenaline, serotonin and GABA axon terminals in the stratum radiatum of adult rat hippocampus (CA1). Hippocampus 5:605-620.

Vogt KE, Regehr WG (2001) Cholinergic modulation of excitatory synaptic transmission in the CA3 area of the hippocampus. J Neurosci 21:75-83.

Woolf NJ (1991) Cholinergic systems in mammalian brain and spinal cord. Prog Neurobiol 37:474-524.

Zarei MM, Radcliffe KA, Chen D, Patrick JW, Dani JA (1999) Distributions of nicotinic acetylcholine receptor alpha7 and beta2 subunits on cultured hippocampal neurons. Neuroscience 88:755-764.

Zorumski CF, Thio LL, Isenberg KE, Clifford DB (1992) Nicotinic acetylcholine currents in cultured postnatal rat hippocampal neurons. Mol Pharmacol 41:931-936. 